\title{
Effect of arbuscular mycorrhizal fungi (AMF) and water stress on growth, phenolic compounds, glandular hairs, and yield of essential oil in basil (Ocimum gratissimum $\mathrm{L}$ )
}

\author{
Zakaria Hazzoumi ${ }^{*}$, Youssef Moustakime ${ }^{1}$, El hassan Elharchli ${ }^{2}$ and Khalid Amrani Joutei ${ }^{1}$
}

\begin{abstract}
Background: Water stress is one of the most adverse conditions that may affect growth, and synthesis of essential oils in aromatic and medicinal plants. To overcome these climatic conditions, mycorrhiza is an adaptation strategy developed by plants to help them cope with these adverse conditions. For this purpose, we studied the influence of mycorrhizal fungi (Glomus intraradices) and water stress on the growth of basil plants (Ocimum gratissimum $\mathrm{L}$ ), the yield of essential oils, and the abundance of glandular hairs.

Results: The analyses show that AMF increases the yield of oils with a maximum recorded in stressed mycorrhizal plants (0.33\%) and the lowest in non-stressed non-mycorrhizal plants (0.22\%). The contents of total phenolic compounds increase in non-mycorrhizal plants under stress (104\% in leaves and 97\% in the roots) unlike the mycorrhiza which did not stimulate the synthesis of these compounds, Moreover, the contents of chlorophyll pigments decrease with the application of stress in non-mycorrhizal plants (53\%) and increase in mycorrhizal plants. The proline contents increased significantly with the application of water stress; this increase is more pronounced in non-mycorrhizal plants than mycorrhizal plants.

Conclusions: Water stress limits the growth and leads to a decrease in morphological parameters, this reduction is accompanied by a synthesis of several molecules in particular proline and phenolic compounds, However, the AMF stimulates growth, and drives the water status in plants at an optimal level, thus confirming the role of mycorrhizal symbiosis in plant defense against biotic and abiotic stress.
\end{abstract}

Keywords: Chlorophyll; Essential oils; Glandular hairs; Glomus intraradices; Phenolic compounds; Proline; O. gratissimum; Water stress

\section{Background}

Permanent or temporary water deficit plays an important role in the distribution of natural vegetation and cultivated in performance more than any other environmental factors plants [1]. It limits the growth and leads to changes in the metabolism of plants. Water stress causes the accumulation of phenols in Bermuda grass (grass) and in Gomphocarpus fruticosus (cotton) [2].

\footnotetext{
* Correspondence: Zakaria.hazzoumi@yahoo.fr

'Laboratory of Bioactive Molecules, Structure and Function, Faculty of Science and Technology Fez, B.P. 2202-Road of Imouzzer, Fez 30000, Morocco

Full list of author information is available at the end of the article
}

Wahid and Ghazanfar [3], Wahid and Close [4] confirmed these data in other plant species, with increased synthesis of phenolic compounds, flavonoids, and phenylpropanoids. Stress-induced increase in the activity of phenylalanine ammonia-lyase (PAL) may be regarded as the beginning of the acclimation of cells facing water stress.

Other studies have shown that severe water stress has a negative effect on the synthesis of these compounds in tobacco; it will stop the synthesis of anthocyanins in flowers and polyphenols in the leaves [5]. A similar phenomenon is observed for the flowers and leaves of Begonia gracilis [6]. 
Studies on osmoregulation indicate that proline plays an important role in the fight against water deficit. Ain-Lhout et al. $[7,8]$ reported that the levels of these molecules increased in Pistacia lentiscus L and Halimium halimifolium $\mathrm{L}$ when they are exposed to water stress. These results are confirmed by the work of AJ Delauney and DPS Delauney and Verma [9], Handa et al. [10], and Heuer [11].

Furthermore, Cornic and Fresneau [12] and Kim et al. [13] suggested that the water stress had a negative effect on the chlorophyll contents, which indicates a decrease in photosynthesis due to a disturbance in the metabolism of carbon and of certain enzymes involved in the regulation of these photosynthetic reactions.

To address these climate hazards and struggle against drought, plants develop several defense strategies; mycorrhizal association with soil fungi is an example [14]. These associations improve plant nutrition, mainly nitrogen and phosphate by increasing water intake in plants by increasing the exchange surface root-soil [15]. Many experiments on the effects of mycorrhizae on plant growth showed that the rate of photosynthesis is higher in mycorrhizal plants compared to non-mycorrhizal plants Auge [16], Kucey and Paul [17], and Levy and Krikun [18]. Most studies suggest that AM fungi contribute to increased rate of photosynthesis in improving $(\mathrm{P})$ nutrition in plants, $[5,19,20]$.

For the establishment of this association, it is necessary that both partners agree. This step is initiated via a crosstalk molecule and a change in gene expression [21]. Furthermore, the AMF infection induces a change in the metabolism of host plants resulting in the induction of chemical defense [22,23]. This change affects the synthesis of several families of molecules, terpenoids [24,25], EOs [26-28], and glucosinolates [29], phytoalexins [30,31], and phenolic compounds [32,33]. Several studies have been carried on the synthesis of these molecules on medicinal and aromatic plants: basil (Ocimum basilicum) [34,35,26,27], oregano (Origanum onites) [28], mint (Mentha requienii [36,37] and Mentha arvensis [36,38]), dill (Anethum graveolens) [39], fennel (Foeniculum vulgare) [40], coriander (Coriandrum sativum) [40,41], lavender (Lavandula angustifolia) [42], pelargonium (Pelargonium peltatum) [43], and sage (Salvia officinalis) [44].

Ocimum gratissimum $\mathrm{L}$ is one of the most used plants in traditional medicine in Morocco. Many studies have been done on this plant [45-47]. This work has focused on improving the yield of EOs. However, the influence of water stress and mycorrhiza on growth and chemical characteristics of this plant is very little studied.

The aim of this work was to evaluate the influence of water stress and inoculation with Glomus intraradices on some physiological and biochemical parameters of $O$. gratissimum L. and synthesis of EOs as well as the abundance of secreting glands of these oils.

\section{Material and methods}

\section{Pregermination of seeds}

The seeds of basil (O. gratissimum L) were surface disinfected by a passage in ethanol $95^{\circ}(1 \mathrm{~min} 30 \mathrm{~s})$ and immersed in a mercury hypochlorite solution (1\%) for 3 to $4 \mathrm{~min}$. Seeds were then rinsed several times in sterile distilled water before being placed on agar medium or on filter paper moistened with sterile distilled water in Petri dishes. Then, placed in an oven at $26^{\circ} \mathrm{C}$, in the dark, to allow germination of the seeds.

\section{Culture basil seedlings}

After germination, seedlings were transplanted into plastic pots (3 $\mathrm{kg}$ capacity) containing the growth substrate in an amount of 50 to 60 plants per pot and were grown in a greenhouse at temperature comprising between 25 and $34^{\circ} \mathrm{C}$.

The basil plants ( $M$ or NM) are watered daily. After the 50th day, the plants are subjected to different water regimes:

a) Water regime unstressed (NS): the plants are not deprived of water throughout their growth.

b) Application of water stress (S): plants are deprived of water for 2 weeks.

\section{Estimation of mycorrhizal root infection}

The identification of mycorrhizal root infection is in optical microscopy through a technique not vital staining with trypan blue (TB), described by Hayman [48], revealing the set of fungal biomass.

Root samples, taken at random, are thoroughly rinsed to remove adhering substrate. Then, the root fragments are digested in a solution of potassium hydroxide $(\mathrm{KOH})$ at $10 \%$ for $45 \mathrm{~min}$ at $90^{\circ} \mathrm{C}$ in an oven, in order to empty the cell of their cytoplasmic contents which facilitates their coloring. Then, the roots are thoroughly rinsed with distilled water and placed in a solution lactophenol trypan blue $(0.5 \%)$ at $90^{\circ} \mathrm{C}$ in the oven for $15 \mathrm{~min}$.

\section{Estimation of mycorrhization}

We used the technique described by Trouvelot et al. [49]. This method allows to judge the state of mycorrhization and reflects the potential of the symbiotic system. Colored roots were cut into fragments of approximately $1 \mathrm{~cm}$ in length. Thirty random fragments are assembled and crushed between slide and cover slip in lactoglycerol, with 15 fragments per slide. Estimating the endomycorrhizal infection is by observing under light microscope. Several parameters are evaluated as follows:

$$
\mathrm{F} \%=(\text { Number of mycorrhizal fragments } / N) \times 100
$$

- (F\%): The frequency of mycorrhization reflects the importance and the percentage of fragments of infected roots. 
with: $N=$ Total number of root fragments observed

- (M\%): The colonization of the cortex intensity expresses the portion of the cortex colonized with respect to the entire root system.

with: $\mathrm{n} 5, \mathrm{n} 4, \ldots, \mathrm{n} 1=$ number of fragments respectively denoted as $5,4, \ldots, 1$.

$\% \mathrm{~m}=M \times($ total number $) /($ number of mycorrhizal fragments $)$
$=M \times 100 / F$

Mycorrhizal intensity:

$$
\% \mathrm{~A}=a \times(M / 100) .
$$

- (A\%): Frequency of arbuscular in the root system.

$$
\% \mathrm{a}=(100 \mathrm{~mA} 3+50 \mathrm{~mA} 2+10 \mathrm{~mA} 1) / 100
$$

Arbuscular intensity of the mycorrhizal part:

where $\mathrm{mA} 3, \mathrm{~mA} 2$, and $\mathrm{mA} 1 \% \mathrm{~m}$ are respectively assigned as $\mathrm{A} 3$ notes, $\mathrm{A} 2$, and $\mathrm{A} 1$.

with: $\mathrm{mA} 3=((95 \mathrm{n} 5 \mathrm{~A} 33 \mathrm{nn} 4 \mathrm{~A} 3+++$ 30n3A3 5n2A3 n1A3 + )/mycorrhizal number $) \times 100 / \mathrm{m}$.

Similarly for A2 and A1.

$$
\% \mathrm{M}=(95 \mathrm{n} 5+70 \mathrm{n} 4+30 \mathrm{n} 3+10 \mathrm{n} 2+\mathrm{n} 1) / \mathrm{N} .
$$

\section{Relative water contents}

The relative water content (RWC) is measured on the seventh or eighth leaf fully developed using the following formula according to Bandurska [50]:

$$
\mathrm{RWC} \%=100 \times[(\mathrm{FW}-\mathrm{DW}) /(\mathrm{WT}-\mathrm{DW})]
$$

With

FW WT

the weight of fresh leaf material.

the weight of fresh material from the turgid leaf was submerged in distilled water for $4 \mathrm{~h}$. DW

dry weight of the sheet material placed in an oven at $70^{\circ} \mathrm{C}$ for $24 \mathrm{~h}$.

\section{Extraction and determination of total phenols}

Oxidation of phenols reduces this reactant in a mixture of the blue oxides of tungsten and molybdenum. The color intensity is proportional to the rate of oxidized phenolic compounds.

- Extraction of TPC.

Fragments of leaves and roots $(0.5 \mathrm{~g})$ were ground in a mortar containing a specific volume usually $5 \mathrm{ml}$, ethanol 50\% (water-alcohol solution). Then, we collect the extracts in tubes with lids and well numbered, then leave the tubes in the refrigerator overnight to allow time for ethanol to extract the maximum amount of phenol present in the extract.

In the tubes containing the leaf extracts, there was a risk of the existence of chlorophylls; we tried to eliminate it by adding in $3 \mathrm{ml}$ of extract $0.5 \mathrm{ml}$ of chloroforms the tubes are vortexed and centrifuged $5 \mathrm{~min}$ at $5 \times$ $1,000 \mathrm{mtp}$; two phases were separated, a phase supernatant and pellet.

-Determination of TPC.

The assay of total phenols using the method based on the Folin-Ciocalteu reagent, described by Ribereau-Gayon and Stonestreet [51].

- Prepare in test tubes the following mixture: $0.5 \mathrm{ml}$ of extract, $3 \mathrm{ml}$ of water, $0.5 \mathrm{ml}$ of $\mathrm{Na} 2 \mathrm{CO} 3(20 \%)$; mix, wait $3 \mathrm{~min}$, and then add $0.5 \mathrm{ml}$ of Folin-Ciocalteu reagent. Mix and place the tubes for $30 \mathrm{~min}$ at $40^{\circ} \mathrm{C}$, reading absorbance at $760 \mathrm{~nm}$.

The amount of phenolic compounds was calculated using gallic acid for the standard curve and expressed in milligrams per gram of fresh leaf matter.

\section{Dosage of proline}

Proline content was determined according to Bates et al. [52] by measuring the quantity of the colored reaction product of proline with ninhydric acid. The absorbance was read at $520 \mathrm{~nm}$. The amount of proline was calculated using L-proline (Panreac) for the standard curve and expressed in micrograms per gram of fresh leaf matter.

\section{Determination of chlorophylls}

Fragments of leaves $(1 \mathrm{~g})$ were ground in a mortar previously placed in ice with a pinch of magnesium carbonate and $5 \mathrm{~g}$ of anhydrous sodium sulfate. Then, $10 \mathrm{ml}$ of acetone $80 \%$ are poured into the ground material, which is filtered on a Buchner; the residue is recovered in tubes essai; and further extractions are carried out with acetone to obtain a filtrate colorless (devoid of all traces of chlorophyll pigments) which the final volume is specified.

OD measurements were made with a spectrophotometer at wavelengths of around 663 to $645 \mathrm{~nm}$ for chlorophyll a and chlorophyll b.

McKinney [53] has established systems of equations that calculate the concentrations $(\mathrm{g} / \mathrm{l})$ of chlorophyll from absorbance at 663 and $645 \mathrm{~nm}$ of an extract of acetone:

$$
\begin{aligned}
& \text { Chlorophyll } \mathrm{a}=(0.0127 \text { D.O663 })-(0.00269 \text { OD 645 }) \\
& \text { Chlorophyll } \mathrm{b}=(0.0229 \text { OD 645 })-(6630.00468 \text { OD }) \\
& \text { Total chlorophyll }=(0.0202 \text { OD 645 })+(0.00802 \text { OD 663 })
\end{aligned}
$$




\section{Extraction of EOs}

One hundred grams of dried aerial parts of O. gratissimum were submitted to hydrodistillation with a Clevenger-type apparatus [54] and extracted with $2 \mathrm{l}$ of water for $180 \mathrm{~min}$ (until no more EO was obtained). The EO was collected, dried under anhydrous sodium sulfate, and stored at $4^{\circ} \mathrm{C}$ until analyzed. The EO yield is given by the following formula:

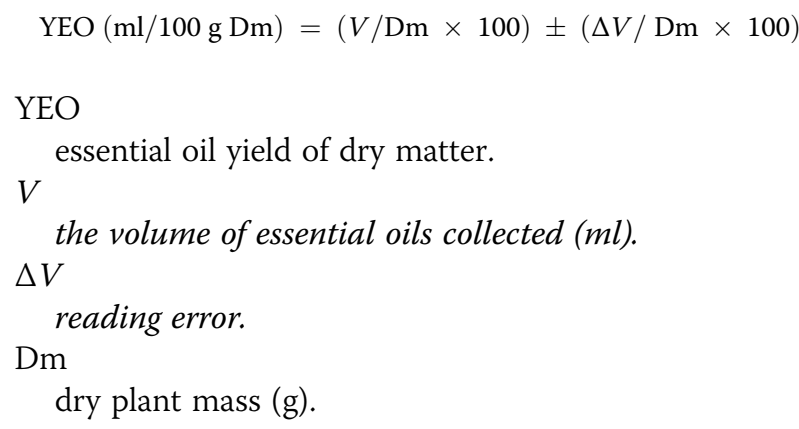

\section{Description of environmental scanning electron microscopy}

The observations were performed using a Scanning Electron Microscope Environmental Quanta 200 (FEI Company, Hillsboro, OR, USA) category. The microscope is equipped with electron gun tungsten. The analyses are carried out under a partial pressure of water vapor.

\section{Statistical analysis}

One-way analysis of variance was carried out for each parameter studied. Tukey's post hoc multiple mean comparison test was used to test for significant differences between treatments (at 5\% level). Univariate analysis was used to test significant differences in treatments, accessions, and their interaction for an individual parameter. All statistical analyses were performed with IBM.SPSS statistics, Version 19. The results of each experiment (biochemical essays) were repeated three times (20 times for morphological essays).

\section{Results}

\section{Mycorrhizal colonization}

Table 1 shows mycorrhizal colonization of basil plants subjected to continuous irrigation (NS) and water stress (S) after disclosure by the trypan blue. This mycorrhizal

Table 1 Mycorrhizal colonization of basil plants (O.gratissimum) roots subjected to continuous irrigation (NS) and water stress (S)

\begin{tabular}{lll}
\hline Mycorrhizal colonization & NS & S \\
\hline Mycorrhizal frequency (F\%) & 78.5 & 77.3 \\
Mycorrhizal intensity (M\%) & 35 & 32 \\
Arbuscular richness (A\%) & 20 & 17 \\
\hline
\end{tabular}

colonization, estimated by the mycorrhizal frequency (F\%), mycorrhizal intensity (M\%), and arbuscular richness (A\%), showed no differences between the stressed plant and nonstressed plant differences.

As against, control plants which were grown in a sterilized soil showed no mycorrhizal colonization.

\section{Effect of mycorrhizae and water stress on plant growth and water contents}

Mycorrhization and stress influenced significantly on the growth of aerial and root part; this elongation of basil plants are largely driven by mycorrhiza with maximum growth recorded in MNS plants. By cons, we find that water stress inhibits the growth of these two parts mainly in NM plants (Figure 1). In stressed mycorrhizal plants, water supply deficit is offset by the AMF which generates growth at the root and aerial part.

The same observations can be made on the water contents in leaves of basil plant; we recorded a significant variation between the different treatments (Figure 2). In MNS plants, mycorrhiza increases the levels of water to a value which can reach 93\%. Non-mycorrhizal plants showed the lowest levels with a dramatic decrease recorded in NMS plants (81\%). In MS plants, there have been relatively high water contents (91\%) reflecting the role of mycorrhizal fungi to withstand water deficit in stressed plants.

\section{Effect of mycorrhizae and water stress on the contents of chlorophyll pigments}

The estimated levels of chlorophyll pigments show that in the absence of water stress, the content of total chlorophyll $(\mathrm{Cha}+\mathrm{Chb})$ is slightly higher $(10 \%)$ in mycorrhizal plants $(2.59 \mathrm{mg} / \mathrm{g}$ MF) than in NM plants ( $2.36 \mathrm{mg} / \mathrm{g} \mathrm{MF})$. This content is reduced by water stress significantly, especially in NM plants. Furthermore, when comparing the levels of these pigments between NM.S and MS plants, we see that mycorrhizal plants accumulate $72.72 \%$ more of chlorophyll (Figure 3 ).

The same observations can be made about the Chla/ Chlb ratio. In the absence of water stress, this ratio is higher in mycorrhizal plants than in NM plants and decreases in times of stress (Figure 3).

\section{Effect of mycorrhizae and water stress on proline contents}

During growth, the proline contents in the aerial part significantly change although in case of irrigation or not, in one hand, and mycorrhization or not in the other (Figure 4).

However, in case of water stress, proline contents increased and this increase is more pronounced in NM plants $(55 \mu \mathrm{g} / \mathrm{g}$ FM) than in M plants $(41 \mu \mathrm{g} / \mathrm{g}$ FM).

At root parts, proline shows the same trend of accumulation for the aerial parts. Thus, proline contents were comparable in unstressed plants inoculated whether or not, while the lack of water leads to an increase in the 


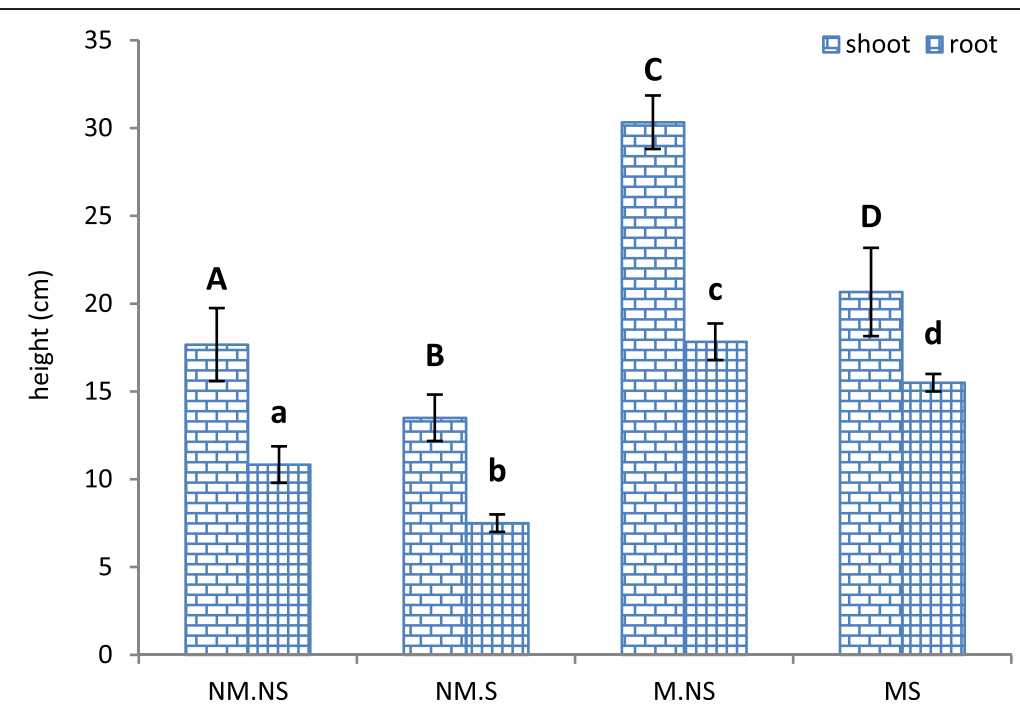

Figure 1 Growth of basil plant. Growth of basil plant (O. gratissimum L) inoculated with (Glomus intraradices) (M) or not (NM) and subjected to water stress (S) or not (NS). The values followed by different letters are significantly different $(P=0.05)$.

synthesis of proline mainly in non-mycorrhizal plants (31 $\mu \mathrm{g} / \mathrm{g}$ FM) (Figure 4).

\section{Effect of mycorrhizae and water stress on phenolic compounds contents}

The contents of TPC in aerial parts do not change significantly when the plants are mycorrhized and in the presence or absence of water stress; however, in nonmycorrhizal plants, these levels increase significantly in stressed plants (4.3 mg/g FM) (Figure 5).
In roots, the levels of TPC increase slightly in the NM. $S$ plants. However, in the other treatment, a difference in the level of this compound was not observed.

\section{EO contents}

The yield of EOs is very influenced by the mycorrhization since we noted a higher synthesis in both cases stress and irrigation. This increase reaches values up to $37 \%$ more than those found in non-mycorrhizal plants; however, water stress did not show a significant

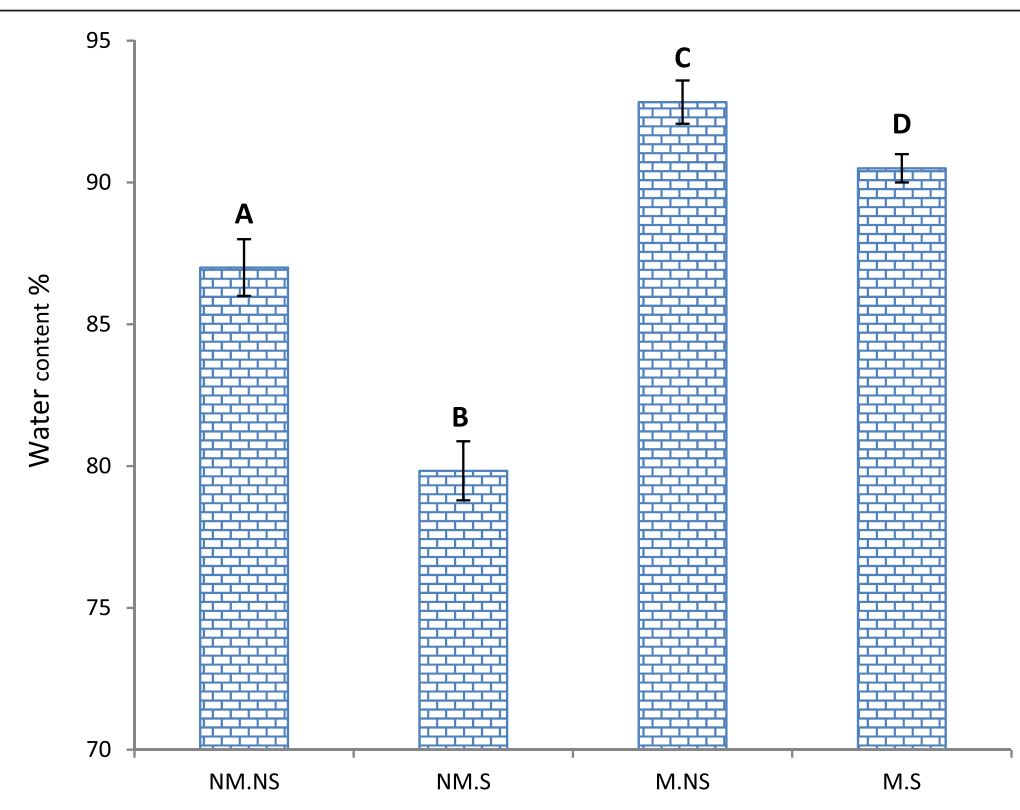

Figure 2 Water contents in basil plant. Water contents in basil plant (O. gratissimum L) inoculated with (Glomus intraradices) (M) or not (NM) and subjected to water stress (S) or not (NS). The values followed by different letters are significantly different $(P=0.05)$. 


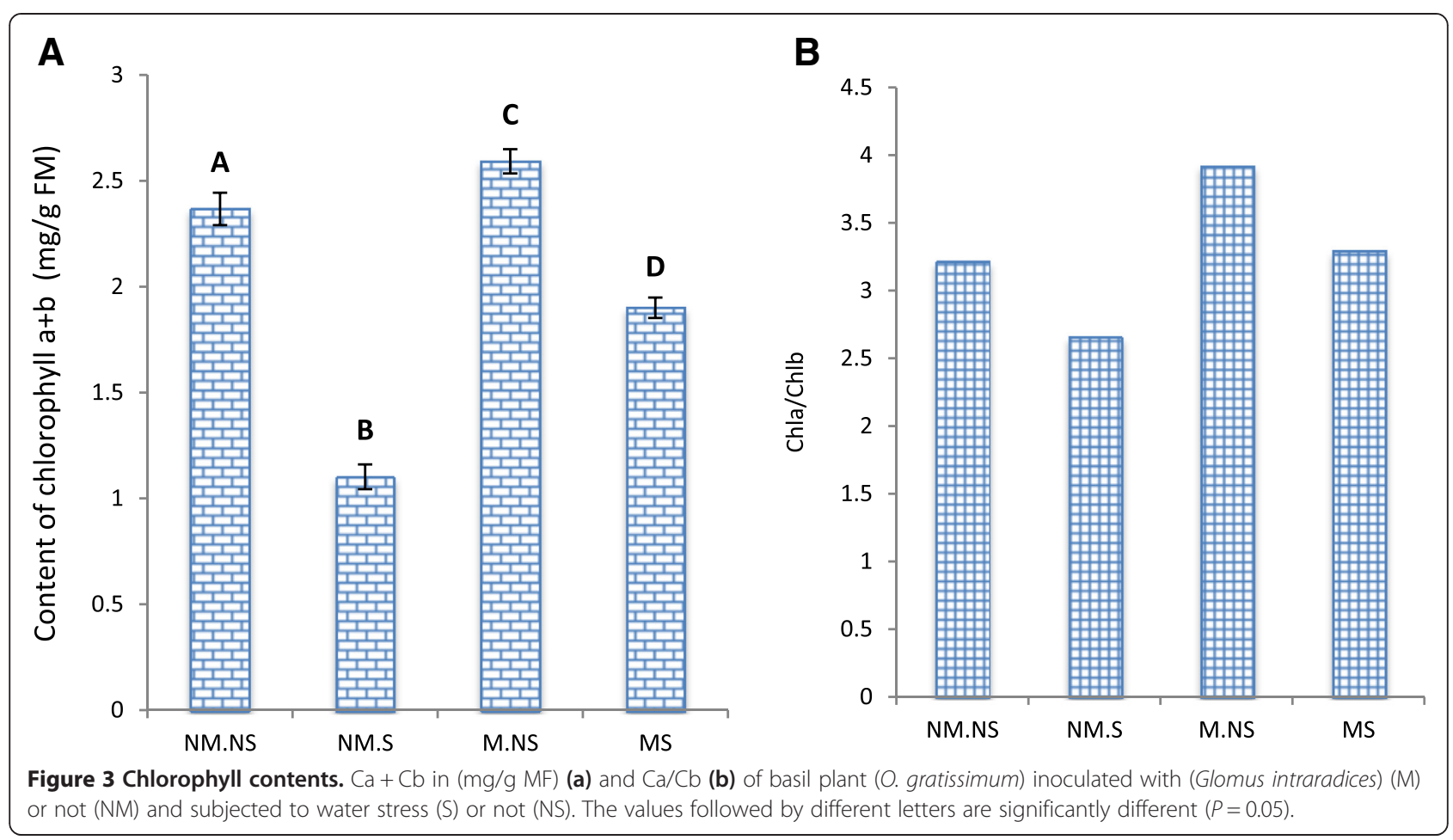

influence on the synthesis of EO because we noticed a slight increase (9\%) between plants NM and (10\%) between $\mathrm{M}$ plants. Moreover, the combination of mycorrhization and stress (MS) increases this value to $50 \%$, greater than those found in NM.NS plants (Table 2).
These results can be confirmed by the increase in the number of glandular hairs in basil leaves (Figure 6). The observations in environmental scanning electron microscopy show an increase in the number of glandular hairs in the basal part of mycorrhizal plants compared to basal

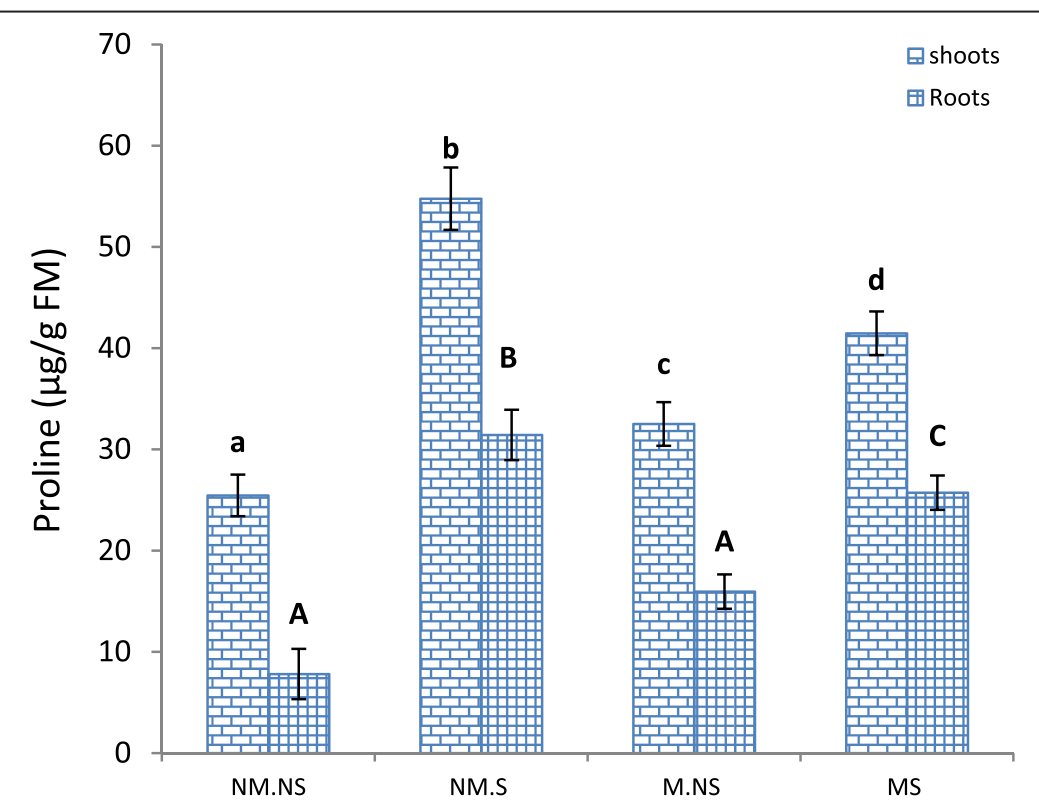

Figure 4 Proline contents in basil plant. Proline contents in basil plant (O. gratissimum L) inoculated with (Glomus intraradices) (M) or not (NM) and subjected to water stress (S) or not (NS). The values followed by different letters are significantly different $(P=0.05)$. 


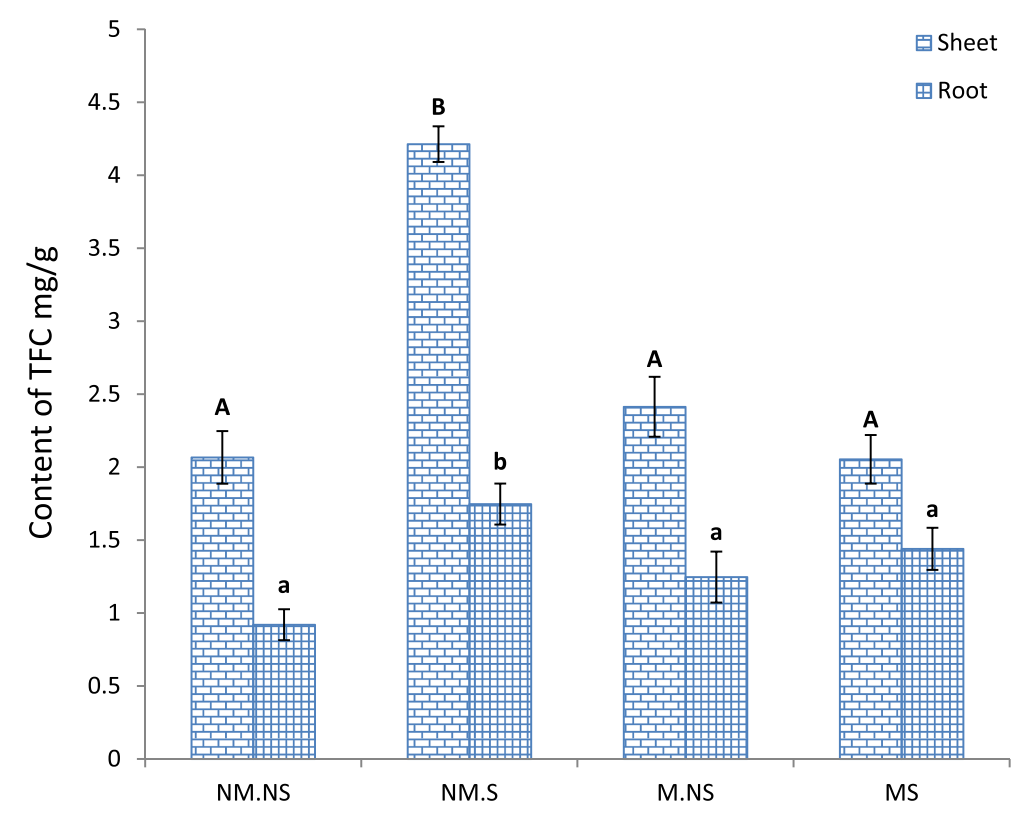

Figure 5 Total phenolic compound contents. Total phenolic compound (TPC) contents in basil plant (O. gratissimum L) inoculated with (Glomus intraradices) (M) or not (NM) and subjected to water stress (S) or not (NS). The values followed by different letters are significantly different $(P=0.05)$.

areas of non-mycorizel plant. The mycorrhization can double the number of the glandular hairs.

\section{Discussion}

The effect of mycorrhizae on basil plant tolerance to water stress is studied using the fungus G. intraradices as mycorrhizal inoculum. Plants inoculated with G. intraradices show better growth than non-inoculated plants, both in terms of irrigation, in conditions of water stress. In irrigated conditions, inoculation with G. intraradices causes an increase in the length of the aerial part and root of the irrigated plants, respectively, $71 \%$ and $75 \%$, while in conditions of water stress, the growth of NM.S plants is limited because stress alters the growth of root parts which influence the water and nutritional status of plants. Under these conditions, mycorrhiza increases the growth of aerial parts of $51 \%$ and root parts of nearly $130 \%$. Similar results are observed by many authors, although the magnitude of adverse effects caused by the water stress and the positive effects of mycorrhizal is very

Table 2 variation of essential oils contents under conditions of stress and mycorrhizal in 0. gtatissimum plants

\begin{tabular}{lllll}
\hline & NM.NS & NM.S & M.NS & MS \\
\hline Oils content (\%) & $0.22 \mathrm{a}$ & $0.24 \mathrm{a}$ & $0.3 \mathrm{~b}$ & $0.33 \mathrm{C}$ \\
\hline
\end{tabular}

Three replications were taken for the extraction of essential oils, the values followed by different letters are significantly different $(P=0.05)$. variable: Ferahani et al. [41] showed that mycorrhizal stressed coriander present a normal growth. An-Dong et al. [20], Baslam et al. [2]), Rasouli-Sadaghianil et al. [55], Toussaint et al. [35], and Zolfaghari et al. [56] showed that mycorrhizal fungi Glomus fasciculatum, Glomus etuonicatum, and G. intraradices stimulate the growth and nutritional status of several plants Lactuca sativa L., Lonicera confusa, O. basilicum L, and Vicia faba L. Water stress induced a reduction of water contents (WC) of non-mycorrhizal plants. In mycorrhizal plants, there has also been a reduction, but this reduction is very small. It maintains water contents at higher levels under conditions of water deficit through the mycorrhizal association is due to a better exploitation of available water in the soil by fungal hyphae [57].

In the case of irrigation, the plants do not seem affected by mycorrhiza as non-mycorrhizal plants have chlorophyll levels comparable to those of mycorrhizal plants. However, in plants subjected to water stress, mycorrhizal colonization by $G$. intraradices reduced the magnitude of the reduction in chlorophyll and maintains its contents at much higher than those of non-mycorrhizal plants since the improvement rate can reach $72 \%$. These results confirm those found by Kucey and Paul [17], Levy and Krikun [18], Snellgrove et al. [58], and Allen et al. [59]; they have shown that mycorrhizal combination stimulates photosynthesis of many aromatic and medicinal plants. These authors reported stimulation of photosynthesis in improving 

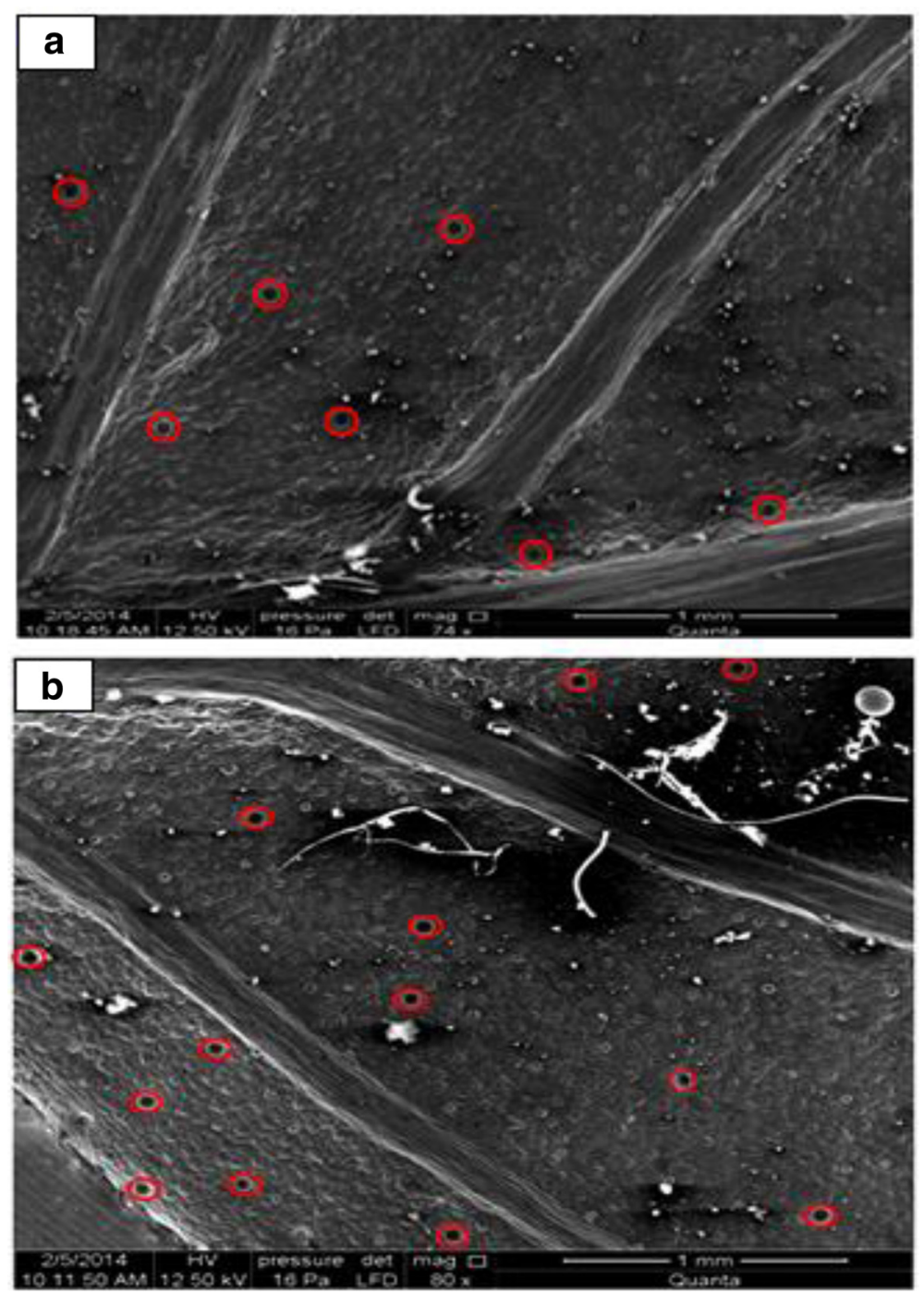

Figure 6 Observation by environmental scanning electron microscopy. Observation by environmental scanning electron microscopy shows the abundance of glandular hairs at the basal part of an unstressed plant and subjected to M (a) or not NM (b).

$\mathrm{P}$ nutrition necessary for reactions of $\mathrm{CO} 2$ assimilation in plants. This stimulation can also be linked to an increase in leaf area [60] or associated with increased hydration leaves [61].

Our results show also, with water stress, proline contents as well as in the aerial parts in root parts increased compared to non-stressed plants. This increase is higher in non-mycorrhizal than in mycorrhizal plants. This latter accumulates proline 39\% less than non-inoculated plants. Mycorrhiza thus mitigates the increase in proline contents in water stress conditions. Similar results are shown by many authors [62,63] who showed that water stress induced proline accumulation in many plants leaves. Proline is a compound that is considered an osmotic regulator $[7,8]$ to promote tolerance to water stress in the stressed plants by maintaining turgor through osmotic adjustment.
We noted also that in case of stress, the proline contents increased slightly in the aerial and root parts when plants are mycorrhizal. This slight increase was due to the defense mechanism set up by the plant response to mycorrhizal infection. According to Giovannetti and Avio [64], the mycorrhizal colonization would initially be perceived by the plant as a stress or an attack at the very location of colonization by endomycorrhizal, where the synthesis of secondary compounds in the early stages of colonization.

We also showed that the levels of TPC increased mainly in the leaves of NMS plants, in response to water stress. These results are in agreement with those of Iker et al. [65] who showed that the levels of flavanols, which are the monomers of condensed tannins (flavanols epicatechin (EC), epicatechin gallate (ECG), and epigallocatechin gallate 
(EGCG), increase in the leaves of Cistus clusii in response to hydric deficit. Most phenols plants are also considered stress metabolites $[66,67]$ and their accumulation in plants is affected by several factors.

We also found in this work that the yield of EO increases significantly when the plants are mycorrhizal. This increase may be related to the number of glandular hairs in the leaves. ESM observations of leaves show an increase in glandular hairs in mycorrhizal plants. These results are confirmed by the work of Andrea Copetta et al. [26,27] who showed that Mycorrhizal colonization of O. basilicum L plants by Glomus mosseae, Gigaspora margarita, and Gigaspora rosea increases the number of glandular hairs in the leaves compared to non-mycorrhizal plants. Zolfaghari et al. [56], Gupta et al. [38], Freitas et al. [36], and Mucciarelli [68] reported an increase in yield of EOs in Mentha arvensis and Mentha piperita L inoculated with mycorrhizal fungi, and this increase related to a change in plant secondary metabolism and the number of glands per leaf; this increase in the levels of EO may also be related to fungal colonization. According to Copetta et al. [26,27], the production of terpenoids and constituents of EOs possess fungicidal properties which are considered a defensive response to colonization by the fungus and causing increased yield and increased production of these metabolites in mycorrhizal plants.

\section{Conclusion}

This study helps us to understand the reaction of O. gratissimum vis-a-vis mycorrhizae and water stress. In the case of non-mycorrhizae, water stress limits the growth and photosynthetic capacity and leads to a reduction of water contents in the plant. This decrease in morphological parameters is accompanied by a synthesis of several molecules in particular proline and phenolic compounds, known for their role in plant tolerance to adverse conditions. However, the AMF stimulates growth and photosynthesis and drives the water status in plant at an optimal level. The results showed a decrease in levels of proline and phenolic compounds, thus confirming the role of mycorrhizal symbiosis in plant defense against biotic and abiotic stress. Note also that this symbiosis leads to an increase in the yield of EOs, regardless of the water status of the plant (stressed or not), and this increase is correlated with the increase of the glandular hairs abundance.

\footnotetext{
Abbreviation

AMF: arbuscular mycorrhizal fungi; Cha: chlorophyll (a); Chb: chlorophyll (b); ChT: chlorophyll (total); EO: essential oil; M.NS: mycorrhizel unstressed; MS: mycorrhizel stressed; NM.NS: non-mycorrhizel unstressed; NM.S: non-mycorrhizel stressed; TPC: total phenolic compounds.
}

\section{Competing interests}

The authors declare that they have no competing interests.

\section{Authors' contributions}

YM, EhE, and KAJ participated in the data processing and in designing the study and performed the statistical analysis and drafting of the manuscript. All authors read and approved the final manuscript.

\section{Acknowledgements}

We would like to thank Pr Naima EL GHACHTOULI from Laboratory of microbial Biotechnology who provided for us the mycorrhizal inoculum, also a special thank for Pr Zain El Abidine Fatemi, from National Institute for Agricultural Research (INRA), Plant Breeding Unit, Meknes-Morocco for statistical help (SPSS software and technical help).

\section{Author details}

${ }^{1}$ Laboratory of Bioactive Molecules, Structure and Function, Faculty of Science and Technology Fez, B.P. 2202-Road of Imouzzer, Fez 30000, Morocco. ${ }^{2}$ Laboratory of microbial Biotechnology, Faculty of Science and Technology Fez, B.P. 2202-Road of Imouzzer, Fez 30000, Morocco.

Received: 3 September 2014 Accepted: 11 February 2015

Published online: 12 April 2015

\section{References}

1. Hong-Bo S, Li-Ye Chu D, Cheruth Abdul J, Chang-Xing Z (2008) Water-deficit stress-induced anatomical changes in higher plants C. R. Biogeosciences 331:215-225

2. Baslam M, Garmendia I, Goicoechea N (2011) Arbuscular mycorrhizal fungi (AMF) improved growth and nutritional quality of greenhouse grown lettuce. J Agric Food Chem 59:5504-5515

3. Wahid A, Ghazanfar A (2006) Possible involvement of some secondary metabolites in salt tolerance of sugarcane. J. Plant Physiol. 163:723-730

4. Wahid A, Close TJ (2007) Expression of dehydrins under heat stress and their relationship with water relations of sugarcane leaves. Biol. Plant. 51:104-109

5. Sivak MN, Walker DA (1986) Photosynthesis in vivo can be limited by phosphate supply. New Phytol 102:499-512

6. Zubek S, Mielcarek S, Turnau K (2012) Hypericin and pseudo hypericin concentrations of a valuable medicinal plant Hypericum perforatum $\mathrm{L}$. are enhanced by arbuscular mycorrhizal fungi. Mycorrhiza 22:149-156

7. Ain-Lhout F, Zunzunegui M, Diaz Barradas MC, Tirado R, Clavijo A, Garcia Novo F (2001) Comparison of proline accumulation in two mediterranean shrubs subjected to natural and experimental water deficit. Plant Soil 230:175-183

8. Ain-Lhout F, Zunzunegui M, Diaz Barradas MC, Tirado R, Clavijo A, Garcia F (2001) Novo Comparison of proline accumulation in two mediterranean shrubs subjected to natural and experimental water deficit. Plant Soil 230:175-183

9. Delauney AJ, Verma DPS (1993) Proline biosynthesis and osmoregulation in plants. Plant J 4:215-223

10. Handa S, Handa AK, Hasegawa PM, Bressan RA (1986) Proline accumulation and the adaptation of cultured plant cells to salinity stress. Plant Physiol 80:938-945

11. Heuer B (1994) Osmoregulatory role of proline in water and salt-stressed plants. In: Pessarakli M (ed) Handbook of Plant and Crop Stress. Marcel Dekker, Inc., New York, pp 363-381

12. Cornic G, Fresneau C (2002) Photosynthetic carbon reduction and carbon oxidation cycles are the main electron sinks for photosystem II activity during a mild drought. Ann Bot 89:887-894

13. Kim JY, Mahe A, Brangeon J, Prioul JL (2000) A maize vacuolar invertase, IVR2, is induced by water stress. Organ/tissue specificity and diurnal modulation of expression. Plant Physiol 124:71-84

14. Wang B, Qiu YL (2006) Phylogenetic distWANG, B., and QIU, Y. L. 2006. Phylogenetic distribution and evolution of mycorrhizas in land plants. Mycorrhiza 16:299-363. ribution and. (s.d.)

15. Smith SE, Read DJ (1997) Mycorrhizal Symbiosis. Academic, London

16. Auge R (2001) Water relations, drought and VA mycorrhizal symbiosis. Mycorrhiza 11:3-42

17. Kucey RMN, Paul EA (1982) Carbon flow, photosynthesis and N2 fixation in mycorrhizal and nodulated fababeans (Vicia faba L). Soil Bioi Biochem 14:407-412

18. Levy Y, Krikun J (1980) Effect of vesicular-arbuscular mycorrhiza on Citrus jambhiri water relations. New Phytol 85:25-31 
19. Marschner H (1995) Mineral Nutrition of Higher Plants. Academic, London

20. An-Dong SH, Qian L, Jian-Guo H, Ling Y (2013) Influence of arbuscular mycorrhizal fungi on growth, mineral nutrition and chlorogenic acid contents of lonicera confusa seedlings under field conditions. Pedosphere 23(3):333-339

21. Harrison M, van Buuren M (1995) A phosphate transporter from the mycorrhizal fungus Glomus versiforme. Nature 378:626-629

22. Pozo M, Azco'n-Aguilar C (2007) Unraveling mycorrhiza-induced resistance. Curr Opin Plant Biol 10:393-398

23. Slezak S, Dumas-Gaudot E, Paynot M, Gianinazzi S (2000) Is a fully established arbuscular mycorrhizal symbiosis required for bioprotection of Pisum sativum root against Aphanomyces euteiches? Mol Plant Microbe Interact 13:238-241

24. Akiyama K, Hayashi H (2002) Arbuscular mycorrhizal funguspromoted accumulation of two new triterpenoids in cucumber roots. Biosci Biotechnol Biochem 66:762-769

25. Rapparini F, Llusia J, Penuelas J (2008) Effect of arbuscular mycorrhizal (AM) colonization on terpene emission and contents of Artemisia annua L. Plant Biol 10:108-122

26. Copetta A, Lingua G, Berta G (2006) Effects of three AM fungi on growth, distribu-tion of glandular hairs, and essential oil production in Ocimum basilicum L. Var Genovese Mycorrhiza 16:485-494

27. Copetta A, Lingua G, Berta G, MASOERO G (2006) Three arbuscular mycorrhizal fungi differently affect growth, distribution of glandular trichomes and essential oil composition in Ocimum basilicum var. Genovese. Proceedings of the 1st International Symposium on the Labiatae: Advances in Production. Biotechnol Utilisation 723:151-156

28. Khaosaad T, Vierheilig H, Nell M, Zitterl-Eglseer K, Novak J (2006) Arbuscular mycorrhiza alter the concentration of essential oils in oregano (Origanum sp., Lamiaceae). Mycorrhiza 16:443-446

29. Vierheilig H, Gagnon H, Strack D, Maier W (2000) Accumulation of cyclohexenone derivatives in barley, wheat and maize roots in response to inoculation with different arbuscular mycorrhizal fungi. Mycorrhiza 9:291-293

30. Sundaresan P, Raja NU, Gunasekaran P (1993) Induction and accumulation of phytoalexins in cowpea roots infected with the mycorrhizal fungus Glomus fasciculatum and their resistance to Fusarium wilt disease. J Biosci 18:291-301

31. Yao MK, Desilets H, Charles MT, Boulanger R, Tweddell RJ (2003) Effect of mycorrhization on the accumulation of rishitin and solavetivone in potato plantlets challenged with Rhizoctonia solani. Mycorrhiza 13:333-336

32. Morandi D (1996) Occurrence of phytoalexins and phenolic compounds on endomycorrhizal interactions, and their potential role in biological control. Plant Soil 185:241-251

33. Rojas-Andrade R, Cerda-Garcia-Rojas CM, Frias-Hernandez JT, Dendooven L, Olalde-Portugal V, Ramos-Valdivia AC (2003) Changes in the concentration of trigonelline in a semi-arid leguminous plant (Prosopis laevigata) induced by an arbuscular mycorrhizal fungus during the presymbiotic phase. Mycorrhiza 13:49-52

34. Pascual-Villalobos MJ, Ballesta-Acosta MC (2003) Chemical variation in an Ocimum basilicum germplasm collection and activity of the essential oil on Callosobruchus maculates. Biochem Syst Ecol 31:673-679

35. Toussaint JP, Smith FA, Smith SE (2007) Arbuscular mycorrhizal fungi can induce the production of photochemicals in sweet basil irrespective of phosphorus nutrition. Mycorrhiza 17:291-297

36. Freitas MSM, Martins MA, Curcino Vieira IJ (2004) Yield and quality of essential oils of Mentha arvensis in response to inoculation with arbuscular mycorrhizal fungi. Pesqui Agropecu Bras 39:887-894

37. Cabello M, Irrazabal G, Bucsinszky AM, Saparrat M, Schalamuk S (2005) Effect of an arbuscular mycorrhizal fungus, Glomus mosseae, and a rock-phosphate-solubilizing fungus, Penicillium thomii, on Mentha piperita growth in a soilless medium. J Basic Microbiol 45:182-189

38. Gupta ML, Prasad A, Ram M, Kumar S (2002) Effect of the vesiculararbuscular mycorrhizal (VAM) fungus Glomus fasciculatum on the essential oil yield related characters and nutrient acquisition in the crops of different cultivars of menthol mint (Mentha arvensis) under field conditions. Bioresour Technol 81:77-79

39. Kapoor R, Chaudhary V, Bhatnagar AK (2007) Effects of arbuscular mycorrhiza and phosphorus application on artemisinin concentration in Artemisia annua L. Mycorrhiza 17:581-587
40. Kapoor R, Giri B, Mukerji KG (2004) Improved growth and essential oil yield and quality in Foeniculum vulgare mill on mycorrhizal inoculation supplemented with P-fertilizer. Bioresour Technol 93:307-311

41. Ferahani HA, Lekaschi MH, Hamidi A (2008) Effects of arbuscular mycorrhizal fungi, phosphorus and water stress on quantity and quality characteristics of coriander. Adv Nat Appl Sci 2:55-59

42. Tsuro M, Inoue M, Kameoka H (2001) Variation in essential oil components in regenerated lavender (Lavandula vera DC) plants. Sci Hortic 88:309-317

43. Perner H, Schwarz P, Bruns C, Maeder P, George E (2007) Effect of arbuscular mycorrhizal colonization and two levels of compost supply on nutrient uptake and flowering of pelargonium plants. Mycorrhiza 17:469-474

44. Nell M, Vötsch M, Vierheilig H, Steinkellner S, Zitterl-Eglseer K, Franz C, Novak J (2009) Effect of phosphorus uptake on growth and secondary metabolites of garden sage (Salvia officinalis L.). J Sci Food Agric 89:1090-1096

45. Hazzoumi Z, Moustakime Y, Khalid A (2014) Effect of gibberellic acid (GA), indole acetic acid (IAA) and benzylaminopurine (BAP) on the synthesis of essential oils and the isomerization of methyl chavicol and trans-anethole in Ocimum gratissimum L. Springer Plus 3:321

46. Madeira SVF, Rabelo M, Soares PMG, Souzaa EP, Meireles AVP, Montenegro C, Limaa RF, Assreuya AMS, Criddle DN (2005) Temporal variation of chemical composition and relaxant action of the essential oil of Ocimum gratissimum L. (Labiatae) on guinea-pig ileum. Phytomedicine 12:506-509

47. Yayi E, Gbenou JD, Léon Akanni A, Mansour M, Jean Claude Chalchat O (2004) gratissimum L., siège de variations chimiques complexes au cours du développement C. R. Chimie 7:1013-1018

48. Hayman P e (1970) Improved procedures for clearing and staining parasite and vesiculaire-arbiscular mycorrhizal fungi for rapid assassment of infection trans. Brit Mycolsoc 55:158-161

49. Trouvelot A, Kough JL, Gianinazzi-Pearson V (1986) Meesure du taux de mycorhization VA d'un système radiculaire. Recherche des méthodes d'estimation ayant une signification fonctionnelle. In: Bay G-P, Gianinazzi S (ed) Physiological aspect of mycorrizea. INRA, Paris, pp 217-221

50. Bandurska H (1991) Akumulacja wolnej proliny jako przejaw metabolicznej reakcji roœlin na dzia3anie stresu wodnego. Wiad. Bot. 35:35-46

51. Ribereau-Gayon P, Stonestreet E (1966) Les composes phénoliques des végétaux

52. Bates LS, Waldren RP, Teare JD (1973) Rapid determination of proline for water stress studies. Plant Soil 39:205-207

53. McKinney (1941) Absorption of light by chlorophyll solutions. J. Biol. Chem. 140:315-332

54. Clevenger JF (1928) Determination of volatile oil. J Ann Pharm Assoc 17 (4):346-351

55. Rasouli-Sadaghianil MH, Hassani A, Barin M, Danesh YR, Sefidkon F (2010) Effects of arbuscular mycorrhizal (AM) fungi on growth, essential oil production and nutrients uptake in basil. J Med Plants Res 4(21):2222-2228

56. Zolfaghari M, Nazeri V, Sefidkon F, Rejali F (2013) Effects Effect of arbuscular mycorrhizal fungi on plant growth and essential oil contents and composition of Ocimum basilicum L. Iran J Plant Physiol 3(2):643-650

57. Davies J, Potter JR, Linderman RG (1993) Drought resistance of mycorrhizal pepper plants independent of leaf $\mathrm{P}$ concentration-response in gas exchange and water relations. Physiol Planta 87:45-53

58. Snellgrove RC, Stribley DP, Tinker PB, Lawlor DW (1986) The effect of vesicular-arbuscular mycorrhizal infection on photosynthesis and carbon distribution in leek plants. See Ref 13:421-424

59. Allen MF, Smith WK, Moore TS, Christensen M (1981) Comparative water relations and photosynthesis of mycorrhizal and non-mycorrhizal Bouteloua gracilis (HBK) Lag ex Steud. New Phytol 88:683-693

60. Fredeen AL, Terry N (1988) Influence of vesicular-arbuscular mycorrhizal infection and soil phosphorus level on growth and carbon metabolism of soybean. Can J Bot 66:2311-2316

61. Snellgrove RC, Splittstoesser WE, Stribley DR, Tinker RB (1982) The distribution of carbon and the demand of the fungal symbiont in leek plants with vesicular-arbuscular mycorrhizas. New Phytol 92:75-S7

62. Ruiz-Lozano JM (2003) Arbuscular mycorrhizal symbiosis and alleviation of osmotic stress. New Perspect Mol Stud Mycorrhiza 13:309-317

63. Rosa LP, dos Santos MA, Matvienko B, dos Santos EO, Sikar E (2004) Greenhouse gases emissions by hydroelectric reservoirs in tropical regions. Climatic Change 66(1-2):9-21

64. Giovannetti M, Avio L (2002) Biotechnology of arbuscular mycorrhizas, Mycorrhizas. In: Khachatourians GG, Arora DK (ed) Applied Mycology and Biotechnology, Vol. 2. Agriculture and Food Production. Elsevier, Amsterdam, pp 275-310 
65. Iker H, Leonor A, Sergi M-b (2004) Drought-induced changes in flavonoids and other low molecular weight antioxidants in Cistus clusii grown under Mediterranean field conditions. Tree Physiol 24:1303-1311

66. Strack D, Fester T, Hause B, Schliemann W, Walter MH (2003) Arbuscular mycorrhiza: biological, chemical and molecular aspects. J Chem Ecol 29:1955-1979

67. Sheppard JW, Peterson JF (1976) Chlorogenic acid and Verticillium wilt of tobacco. Can J Plant Sci 56:157-160

68. Mucciarelli M, Scannerini S, Bertea C, Maffei M (2003) In vitro and in vivo peppermint (Mentha piperita) growth promotion by nonmycorrhizal fungal colonization. New Phytologist 158(3):579-591

Submit your manuscript to a SpringerOpen ${ }^{\circ}$ journal and benefit from:

- Convenient online submission

- Rigorous peer review

- Immediate publication on acceptance

- Open access: articles freely available online

- High visibility within the field

- Retaining the copyright to your article

Submit your next manuscript at $>$ springeropen.com 